\title{
Tropospheric Attenuation in GeoSurf Satellite Constellations
}

\author{
Emilio Matricciani *(D, Carlo Riva (D) and Lorenzo Luini \\ Dipartimento di Elettronica, Informazione e Bioingegneria, Politecnico di Milano, Piazza L. da Vinci, 32 , \\ 20133 Milano, Italy; Carlo.Riva@polimi.it (C.R.); Lorenzo.Luini@polimi.it (L.L.) \\ * Correspondence: Emilio.Matricciani@polimi.it
}

Citation: Matricciani, E.; Riva, C.;

Luini, L. Tropospheric Attenuation in GeoSurf Satellite Constellations.

Remote Sens. 2021, 13, 5180.

https://doi.org/10.3390/rs13245180

Academic Editors: Alberto Gotta and Tomaso de Cola

Received: 5 November 2021

Accepted: 17 December 2021

Published: 20 December 2021

Publisher's Note: MDPI stays neutral with regard to jurisdictional claims in published maps and institutional affiliations.

Copyright: (c) 2021 by the authors. Licensee MDPI, Basel, Switzerland. This article is an open access article distributed under the terms and conditions of the Creative Commons Attribution (CC BY) license (https:/ / creativecommons.org/licenses/by/ $4.0 /)$.

\begin{abstract}
In GeoSurf satellite constellations, any transmitter/receiver, wherever it is located, is linked to a satellite with zenith paths. We have studied the tropospheric attenuation predicted for some reference sites (Canberra, Holmdel, Pasadena, Robledo, and Spino d'Adda), which also set the meridian along which we have considered sites with latitudes ranging between $60^{\circ} \mathrm{N}$ and $60^{\circ} \mathrm{S}$. At the annual probability of $1 \%$ of an average year, in the latitude between $30^{\circ} \mathrm{N}$ and $30^{\circ} \mathrm{S}$, there are no significant differences between GEO slant paths and GeoSurf zenith paths. On the contrary, at $0.1 \%$ and $0.01 \%$ annual probabilities, large differences are found for latitudes greater than $30^{\circ} \mathrm{N}$ or $30^{\circ} \mathrm{S}$. For comparing the tropospheric attenuation in GeoSurf paths with that expected in LEO highly variable slant paths, we have considered, as reference, a LEO satellite constellation orbiting in circular at $817 \mathrm{~km}$. GeoSurf zenith paths "gain" several dBs compared to LEO slant paths. The more static total clear-sky attenuation (water vapor, oxygen, and clouds) in both GEO and LEO slant paths shows larger values than GeoSurf zenith paths. Both for rain and clear-sky attenuations, Northern and Southern Hemispheres show significant differences.
\end{abstract}

Keywords: GEO; LEO; satellite constellations; GeoSurf; rain attenuation; clear-sky attenuation

\section{The GeoSurf Satellite Constellations}

The GeoSurf satellite constellations belong to the family of Walker Star Constellations [1]. The GeoSurf constellations emulate, for ground stations located at any latitude, the geostationary orbit with zenith paths: any transmitter/receiver, wherever it is located, can be linked to a satellite as if it were at the equator and the satellite at its zenith. The GeoSurf constellations can have most of the advantages of the current GEO (Geostationary), MEO (Medium Earth Orbit), and LEO (Low Earth Orbit) satellite constellations without having most of their drawbacks. For comparing the advantages and disadvantages of a GeoSurf constellation design, see Table 1 in [1].

In the present paper, our aim is to estimate, globally, the tropospheric attenuation that can be expected in the GeoSurf links at $39.6 \mathrm{GHz}$ - a frequency experimented with the satellites Italsat [2,3] and Alphasat [4,5]—due to clear-sky (water vapor, oxygen, and clouds) and to rain, in terms of the probability of annually exceeding a given fade level. For link budgets, this fade level is to be considered as the largest power/coding margin that must be available before link outage. Aside from frequency, of course, clear-sky and rain fades depend on the site and elevation angle under which the satellite is seen from the ground station-practically $90^{\circ}$, i.e., zenith, in the GeoSurf constellations-not on the satellite altitude; therefore, they can be globally applied to any GeoSurf constellation, regardless of orbit altitude.

For the purpose of illustration, we have studied the tropospheric attenuation predicted for the reference sites listed in Table 1 (Canberra, Holmdel, Pasadena, Robledo, and Spino $\mathrm{d}^{\prime}$ Adda) to show, with some prediction models, the tropospheric attenuation expected there in GeoSurf (zenith) links, in GEO links with satellites located at the same longitude of the site (GEO largest elevation angle), and in LEO links. These specific sites have been chosen because historical radio propagation experiments have been conducted there for 
many years (Holmdel in New Jersey, Spino d'Adda in Italy) or because they are the seats of important space stations (Canberra in Australia, Robledo in Spain) or space laboratories (Jet Propulsion Laboratory, Pasadena in California).

These reference sites set the meridian on which we consider sites with latitudes ranging between $60^{\circ} \mathrm{N}$ and $60^{\circ} \mathrm{S}$, and report the tropospheric attenuation predicted first for GEO and GeoSurf satellites along the meridian and then for LEO satellites. In other words, we sample Earth longitude along these meridians and sample Earth latitude in a continuous range between $60^{\circ} \mathrm{N}$ and $60^{\circ} \mathrm{S}$. The choice of this particular latitude range is just due to the fact that for larger latitudes, the GEO paths would be too low on the horizon to be practical and useful, because they can be obstructed and suffer from large fades, due either to rain or to clear sky, and large scintillations. On the contrary, it is obvious that MEO, LEO, and GeoSurf satellites can always be used at any latitude, with the advantages and disadvantages discussed in [1].

Table 1. Reference sites.

\begin{tabular}{ccccc}
\hline Station & Latitude & Longitude & Altitude (m) & $\begin{array}{c}\text { GEO Elevation } \\
\text { Angle ( })^{\circ} \text { on the } \\
\text { Local Meridian }\end{array}$ \\
\hline Canberra (Australia) & $35.30^{\circ} \mathrm{S}$ & $149.10^{\circ} \mathrm{E}$ & 597 & 49.0 \\
\hline Holmdel (New Jersey) & $40.40^{\circ} \mathrm{N}$ & $74.10^{\circ} \mathrm{W}$ & 23 & 43.3 \\
\hline Pasadena (California) & $34.15^{\circ} \mathrm{N}$ & $118.00^{\circ} \mathrm{W}$ & 352 & 50.3 \\
\hline Robledo (Spain) & $40.87^{\circ} \mathrm{N}$ & $4.25^{\circ} \mathrm{W}$ & 987 & 42.8 \\
\hline Spino d'Adda (Italy) & $45.40^{\circ} \mathrm{N}$ & $9.50^{\circ} \mathrm{E}$ & 82 & 37.7 \\
\hline
\end{tabular}

After this introductory section, Section 2 reports and discusses the probability distributions of rain attenuation at the reference sites in the GEO paths along the meridian; Section 3 reports and discusses the GeoSurf probability distributions of rain attenuation obtained along the meridian of the reference sites in the latitude range of $60^{\circ} \mathrm{N}$ to $60^{\circ}$ $\mathrm{S}$; Section 4 reports and discusses the expected tropospheric attenuation affecting LEO satellites; Section 5 reports and discusses similar results but for clear-sky attenuation; and finally, Section 6 reports some final remarks and suggests future work.

\section{GEO Probability Distributions of Rain Attenuation at the Reference Sites}

Let us consider Spino d'Adda. In the countryside of this town, there is a small space station of Politecnico di Milano where, since the 1970s, the Italian National Research Council (CNR) first, and the Italian Space Agency (ASI) later, with the experts of Politecnico di Milano, have conducted radio propagation and telecommunication experiments at $\mathrm{Ku}$ and Ka frequency bands, with the satellites SIRIO [6], ITALSAT [7], and currently Alphasat, within the framework of the Aldo Paraboni experiment [4,5].

In Figure 1, we show the annual probability distributions (\%) of exceeding rain attenuation $(\mathrm{dB})$ in the slant path in Spino d'Adda to a geostationary satellite on the meridian (elevation angle $37.7^{\circ}$, see Table 1 ) at $39.6 \mathrm{GHz}$ and a circular polarization. Rain attenuation is calculated by using, as input, the rain rate probability distribution recorded locally—with rain rate expressed in millimeters per hour-in the years 1993-2002 (10 years of continuous observation). In other words, we simulate links towards GEO satellites with the highest elevation angle.

The prediction models applied are those known in the literature as "Brazil" [8], Bryant [9], Excell [10], Flavin [11], Garcia [12], Global Synthetic Storm Technique (SST glo) [13], Svyatogor [14], and the current ITU-R model [15]. The choice of these particular prediction models is mainly due to their global applicability for later calculations. For predictions at low latitudes, we have not considered the ITU-R model because it predicts doubtful results at these latitudes when the slant path elevation angle is large. We consider 
this model later because at the latitudes of the reference sites listed in Table 1, with the slant paths elevation angles indicated there, its predictions are reliable (see Section 4).

Finally, note that it is not the aim of this paper to test the various models, an activity that has been carried out several times (e.g., [16]). They are only used to show the possible range of predictions, although we observe that the Svyatogor model predicts largely pessimistic values, just at the largest probabilities where most direct user applications are envisaged at the Ka band.

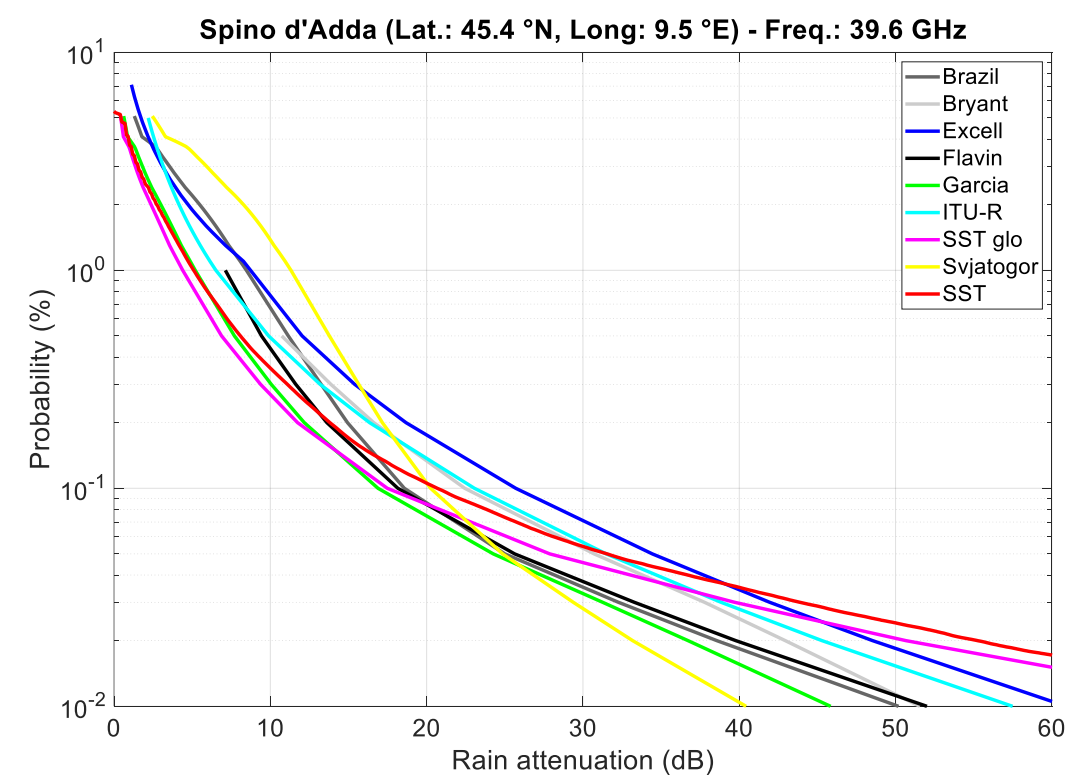

Figure 1. Annual probability distributions (\%) of rain attenuation exceeded in the slant path at Spino $\mathrm{d}^{\prime}$ Adda to a geostationary satellite (elevation angle $37.7^{\circ}$ ) on the meridian, at $39.6 \mathrm{GHz}$ and a circular polarization, calculated by the indicated prediction models, using, as input, the rain rate probability distribution recorded locally, with rain rate expressed in millimeters per hour, in the years 1993-2002. The solid red line refers to using the full SST [17], whose input is the full set of rain rate time series recorded in the same period of time, whose probability distribution is used as input to the models.

In Figure 1, the full Synthetic Storm Technique (SST) prediction is also reported (red solid curve). This is the classical SST [17], which transforms the rain rate time series into the rain attenuation time series and gives very reliable predictions of both firstorder statistics, i.e., probability distributions of rain attenuation [18-23], and second-order statistics (parameters dependent on the time evolution of rain attenuation, such as, for example, fade durations) [24-27]. Therefore, its probability distribution should be the closest to real measurements. The full SST should always be used whenever rain rate time series are locally available. The global SST (SST glo in Figure 1) only mimics the probability distribution of the full SST, and similar to the other models mentioned, it only needs, as input, the annual probability distribution of rain rate, expressed in millimeters per hour, either given by local measurements or by the ITU-R [28].

Let us now consider the other reference sites. In Figure 2, we show the probability distributions of rain attenuation predicted for the slant path to a GEO satellite along the meridian of the site, by using the ITU $-\mathrm{R}$ rain rate probability distributions as input to the models and its rain height [29]. The elevation angle at each site is reported in Table 1. For comparing, at a glance, the rain attenuation exceeded at the same probability level, the scales are kept fixed for all figures. 


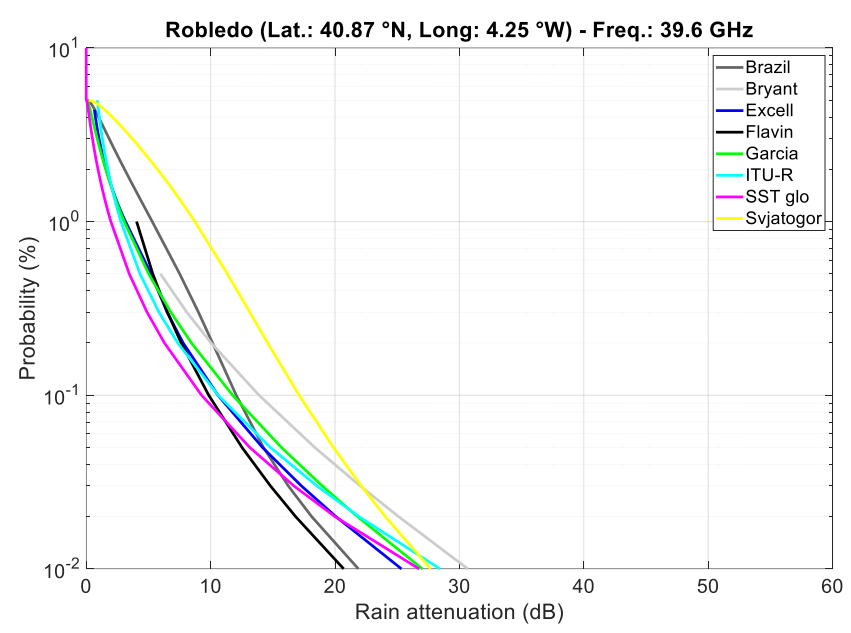

(a)

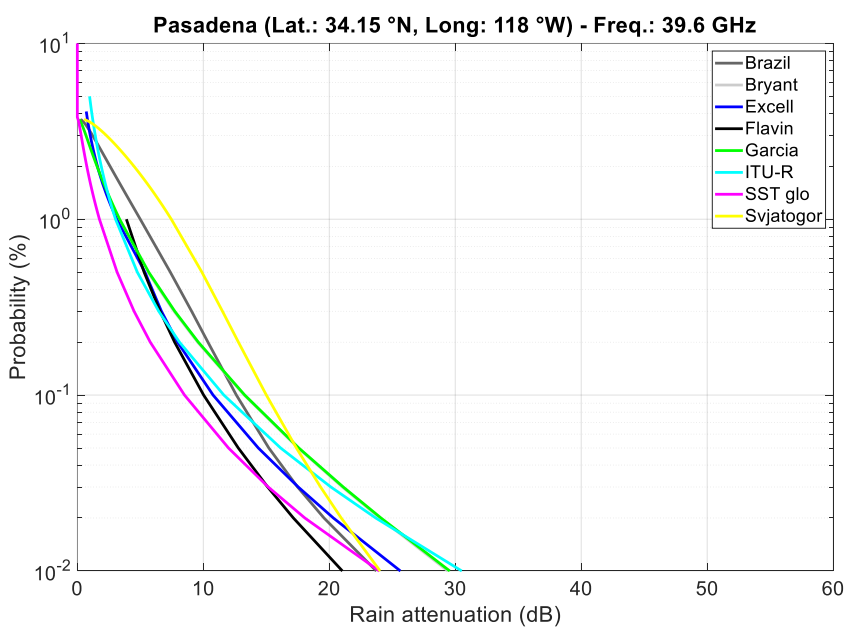

(c)

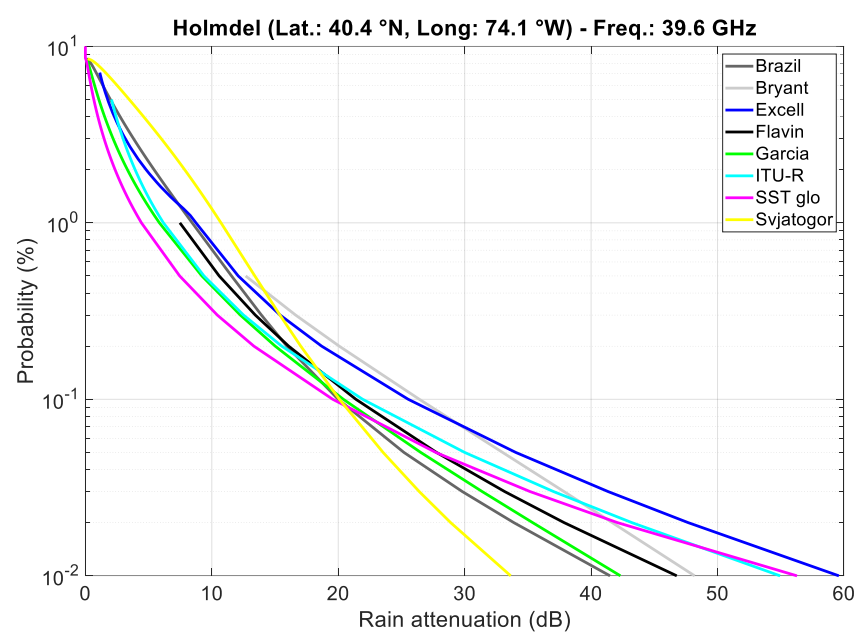

(b)

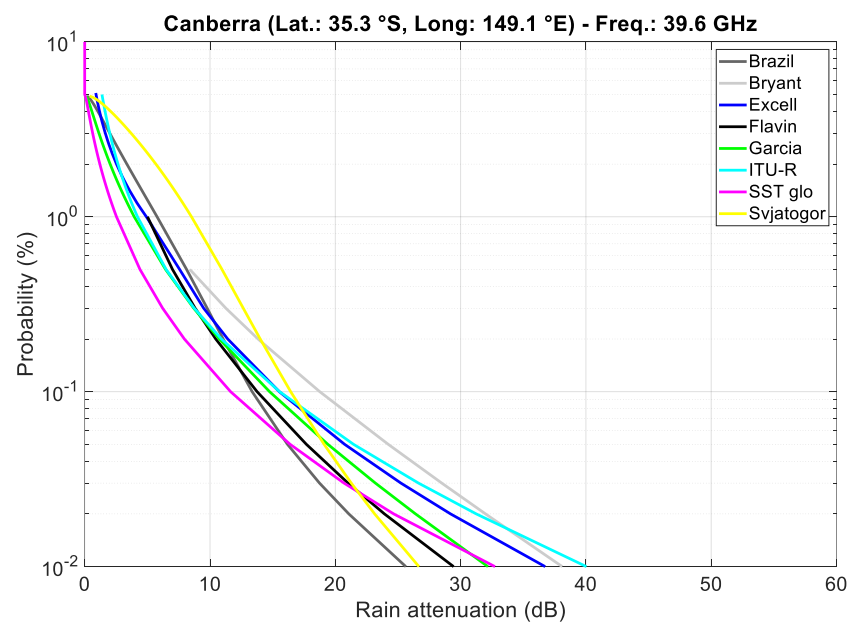

(d)

Figure 2. Annual probability distributions (\%) of rain attenuation exceeded in the slant paths directed along the local meridian to a Geostationary satellite at $39.6 \mathrm{GHz}$ and a circular polarization in: (a) Robledo (elevation angle $42.8^{\circ}$ ): (b) Holmdel (elevation angle 43.3 ${ }^{\circ}$, (c) Pasadena (elevation angle 50.3 ${ }^{\circ}$, and (d) Canberra (elevation angle 49.0), predicted by using the ITU $-\mathrm{R}[28,29]$ rain rate probability distributions.

Of course, each site, because of the local climate, shows very different results. However, we must comment that, excluding the full SST, which is very reliable, all other models give predictions within too large a range to be really useful in link design, as a few more dBs in the link margin come at a cost. For example, at $0.1 \%$, the full SST predicts $20.5 \mathrm{~dB}$ in Spino d'Adda (Figure 1), but the predictions range from 17 to $26 \mathrm{~dB}$, a large range for any cost-effective design. In Figure 2, we notice similar large ranges at $0.1 \%$ : from 9 to $18 \mathrm{~dB}$ in Robledo, from 20 to $27 \mathrm{~dB}$ in Holmdel, from 8 to $15 \mathrm{~dB}$ in Pasadena, and from 12 to $19 \mathrm{~dB}$ in Canberra.

However, the results reported in Figures 1 and 2 are useful for our exercise, because in the next section, we compare them with those obtainable in paths with a $90^{\circ}$ elevation angle (GeoSurf), i.e., at the local zenith. This just a first and rough approach to studying the tropospheric attenuation in GeoSurf constellations because a more significant comparison should be done with the slant paths in LEO constellations-with elevation angles largely variable-a task beyond the scope of this paper, except for a single case, as we show in Section 4. 


\section{Global GeoSurf Probability Distributions of Rain Attenuation}

In this section, we consider the meridian of the reference sites and run the prediction models along each meridian in the latitude range $60^{\circ} \mathrm{N}$ to $60^{\circ} \mathrm{S}$. Our aim is to compare the GEO links with the GeoSurf links, as we have done for the reference sites. The input to the models is again the rain rate probability distribution given by the ITU-R. In particular, we show the difference $A_{G E O}-A_{Z}(\mathrm{~dB})$, calculated at selected annual probabilities, between the rain attenuation exceeded in the GEO path, $A_{G E O}(\mathrm{~dB})$, and the rain attenuation exceeded in the GeoSurf path, $A_{Z}(\mathrm{~dB})$, i.e., at the zenith.

Figure 3 shows the results for the longitude of Spino d'Adda, $9.5^{\circ} \mathrm{E}$ (see Table 1), for probabilities exceeded for $1 \%, 0.1 \%$, and $0.01 \%$ of an average year. The difference obtainable specifically at Spino d'Adda can be read at the latitude of $45.4^{\circ} \mathrm{N}$.

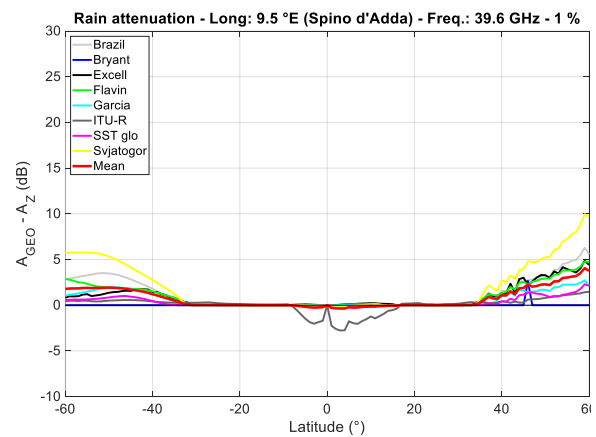

(a)

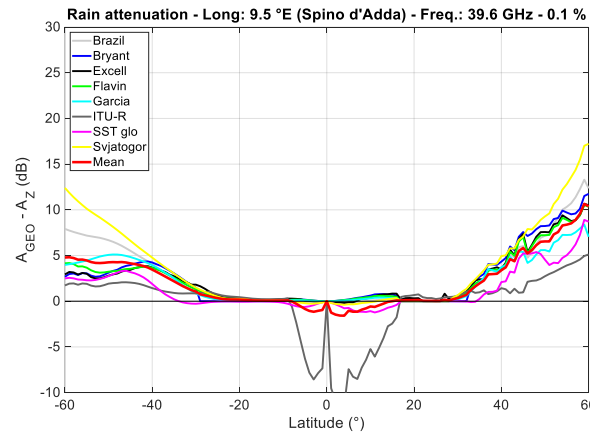

(b)

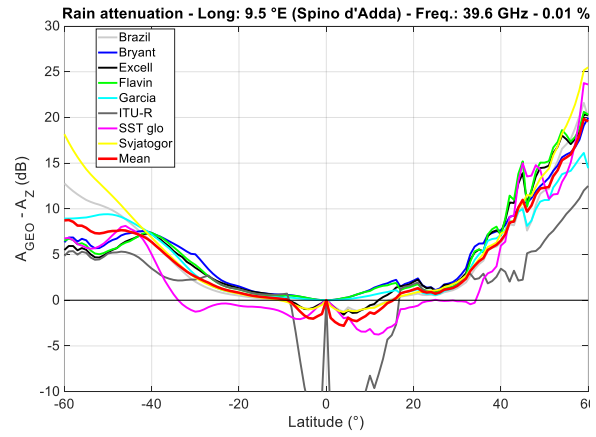

(c)

Figure 3. The difference $A_{G E O}-A_{Z}(\mathrm{~dB})$, calculated at fixed annual probabilities $1 \%(\mathbf{a}) 0.1 \%$ (b), and $0.01 \%$, (c) between the rain attenuation exceeded in the GEO path, $A_{G E O}(\mathrm{~dB})$, and the rain attenuation exceeded in the GeoSurf path, $A_{Z}(\mathrm{~dB})$, i.e., at the zenith in Spino d'Adda; 39.6 GHz, circular polarization.

We can observe some interesting findings:

1. At $1 \%$ probability (Figure 3, left panel), rain attenuation is due to low values of rain rate; therefore, we expect it is produced by a rather uniform rain rate spatial field. This yields limited differences between GEO and GeoSurf paths for GEO high elevation angles (close to $90^{\circ}$ ), as is the case for latitudes between $30^{\circ} \mathrm{N}$ and $30^{\circ} \mathrm{S}$, the range in which there are no significant differences between Northern and Southern Hemispheres.

2. Significant differences are found for latitudes greater than $30^{\circ} \mathrm{N}$ or $30^{\circ} \mathrm{S}$. Now, the GeoSurf $\left(90^{\circ}\right.$ path) and the GEO paths intersect tracts of rain cells which can be significantly diverse. At these latitudes, the GeoSurf paths are less attenuated than the GEO paths. For example, at $60^{\circ} \mathrm{N}$, the average difference $A_{G E O}-A_{Z}$ predicted is about $5 \mathrm{~dB}$ at $1 \%$ probability, $11 \mathrm{~dB}$ at $0.1 \%$ (middle panel), and $20 \mathrm{~dB}$ at $0.01 \%$ (right panel).

3. In the low latitude range of $\sim 20^{\circ} \mathrm{N}$ to $\sim 20^{\circ} \mathrm{S}$ (GEO elevation angle along the meridian is larger than about $67^{\circ}$ ), the difference $A_{G E O}-A_{Z}$ is quite small and even negative for some models at probability $0.01 \%$, especially for Excell and Global SST. This latter model retains, in fact, some spatial features of the full SST, which at high elevation angles, such as those found in this latitude range $\left(>67^{\circ}\right)$, samples the small high-intensity rain cells differently compared to the zenith path (see [13]). In this range, desert areas, such as the Sahara Desert, also affect the results, of course.

4. Notice that in the low latitude range of $\sim 20^{\circ} \mathrm{N}$ to $\sim 20^{\circ} \mathrm{S}$, the difference $A_{G E O}-A_{Z}$ predicted by the ITU $-\mathrm{R}$ model is extremely large.

5. Northern and Southern Hemispheres show significant differences as probability decreases, especially for the larger latitudes.

Figures 4-7 show similar results concerning the longitude of the other reference sites. However, it is very interesting to notice the large negative difference ( 5 to $8 \mathrm{~dB}$ ) found at 
a probability of $0.01 \%$ for sites along the meridian of Holmdel $\left(74.1^{\circ} \mathrm{W}\right)$ in the latitude range of $\sim 10$ to $\sim 30^{\circ} \mathrm{N}$, a region that includes Florida and the Carebbean Islands. Similar observations can be done at a probability of $0.01 \%$ for the longitudes, such as the longitudes of Pasadena $\left(118^{\circ} \mathrm{W}\right)$ and Canberra $\left(149.1^{\circ} \mathrm{E}\right)$, which include desert areas and the ocean.

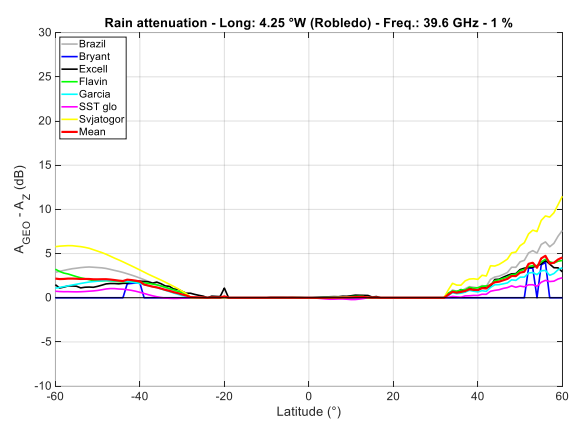

(a)

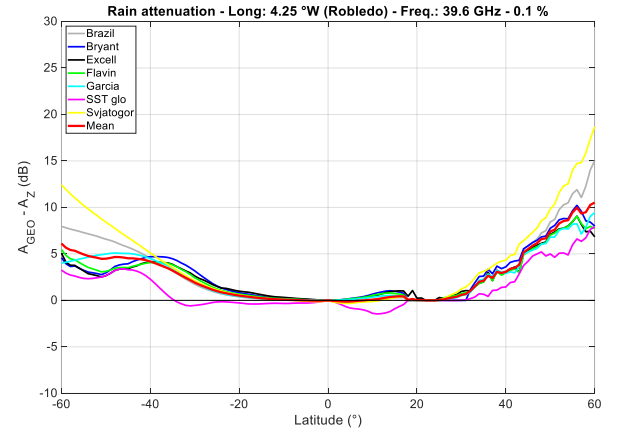

(b)

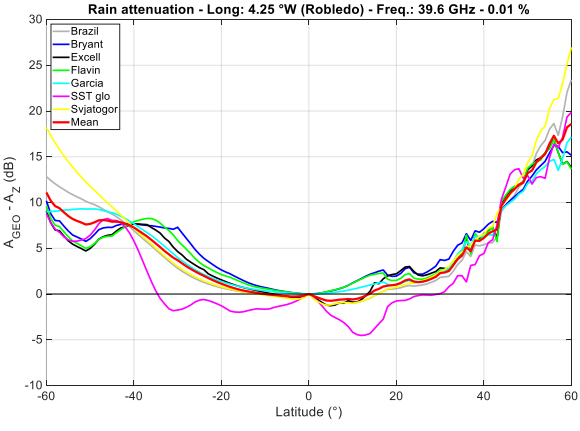

(c)

Figure 4. The difference $A_{G E O}-A_{Z}$, calculated at fixed annual probabilities $1 \%(\mathbf{a}), 0.1 \%(\mathbf{b})$, and $0.01 \%$ (c), between the rain attenuation exceeded in the GEO path, $A_{G E O}$, and the rain attenuation exceeded in the GeoSurf path, $A_{Z}$, i.e., at the zenith in Robledo; $39.6 \mathrm{GHz}$, circular polarization.

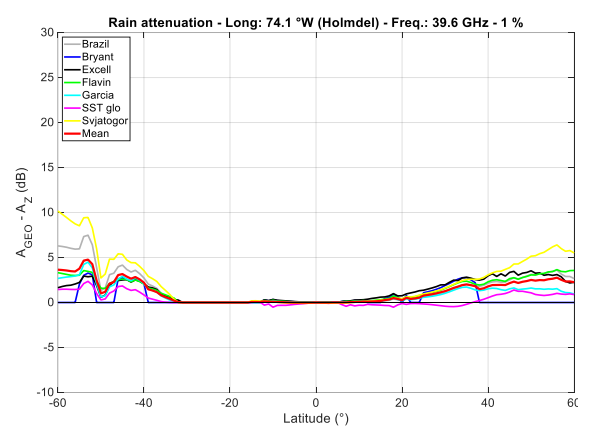

(a)

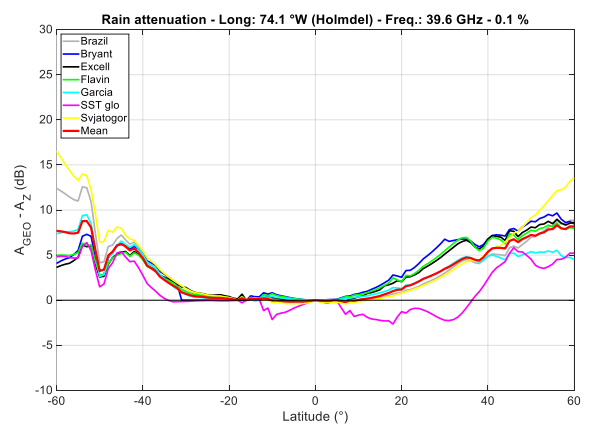

(b)

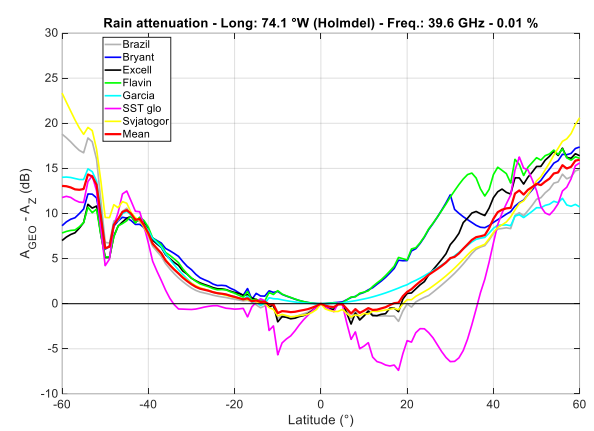

(c)

Figure 5. The difference $A_{G E O}-A_{Z}$, calculated at fixed annual probabilities $1 \%(\mathbf{a}), 0.1 \%(\mathbf{b})$, and $0.01 \%$ (c), between the rain attenuation exceeded in the GEO path, $A_{G E O}$, and the rain attenuation exceeded in the GeoSurf path, $A_{Z}$, i.e., at the zenith in Holmdel; $39.6 \mathrm{GHz}$, circular polarization.

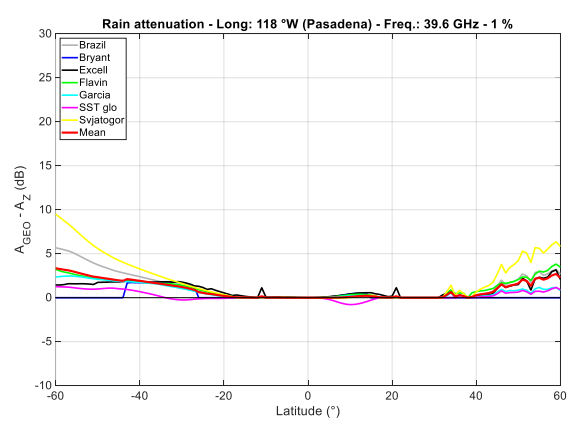

(a)

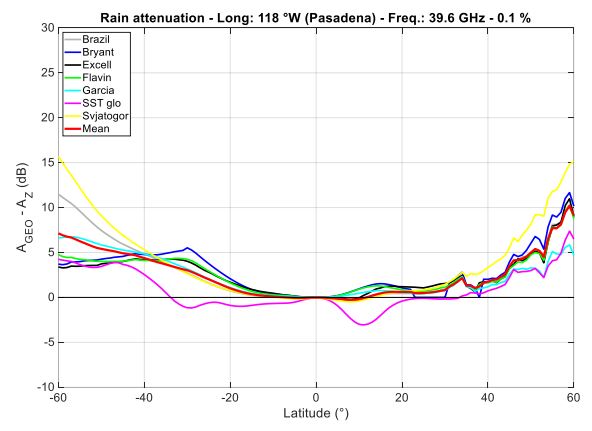

(b)

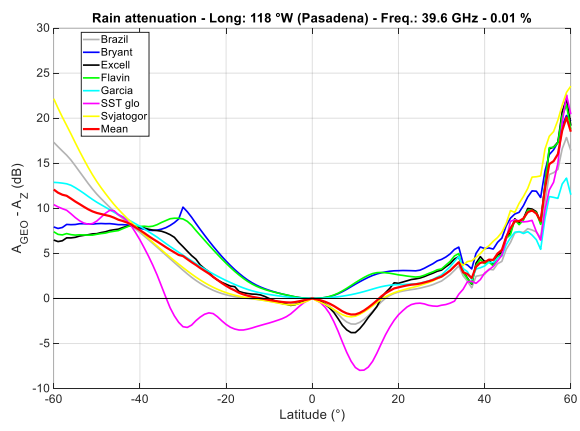

(c)

Figure 6. The difference $A_{G E O}-A_{Z}$, calculated at fixed annual probabilities $1 \%(\mathbf{a}), 0.1 \%(\mathbf{b})$, and $0.01 \%$ (c), between the rain attenuation exceeded in the GEO path, $A_{G E O}$, and the rain attenuation exceeded in the GeoSurf path, $A_{Z}$, i.e., at the zenith in Pasadena; 39.6 GHz, circular polarization. 


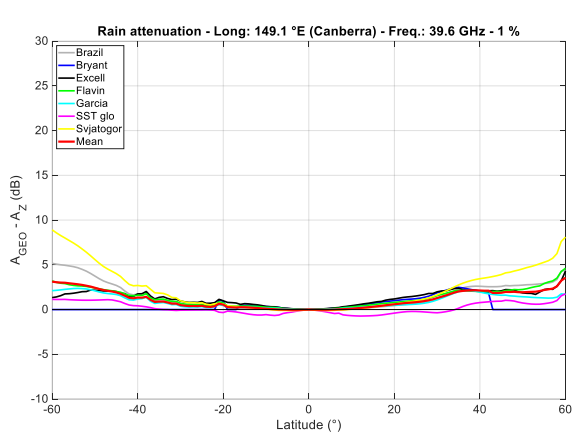

(a)

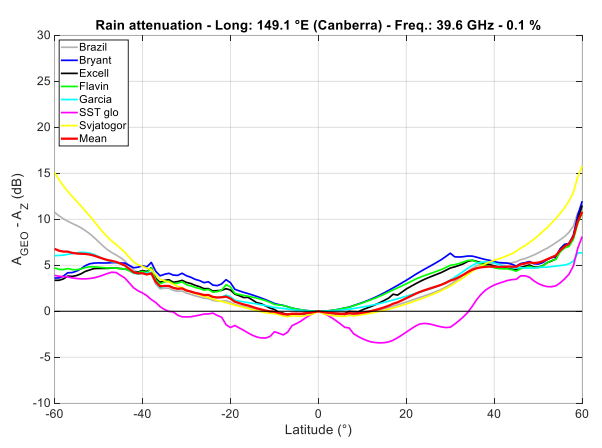

(b)

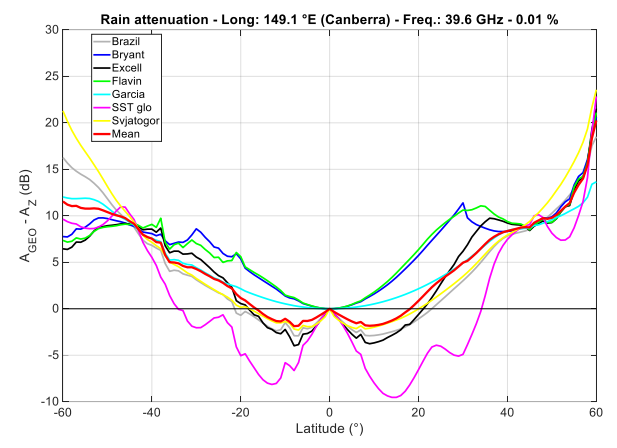

(c)

Figure 7. The difference $A_{G E O}-A_{Z}$, calculated at fixed annual probabilities $1 \%(\mathbf{a}), 0.1 \%(\mathbf{b})$, and $0.01 \%$ (c), between the rain attenuation exceed in the GEO path, $A_{G E O}$, and the rain attenuation exceed in the GeoSurf path, $A_{Z}$, i.e., at the zenith in Pasadena; $39.6 \mathrm{GHz}$, circular polarization.

In these figures, we have not further shown the ITU-R predictions because this model gives unexplainable large differences, $A_{G E O}-A_{Z}$, at low latitudes, as it does for the Spino $\mathrm{d}$ 'Adda longitude. These values are very different from the values predicted by the other models, especially those based on some physical insight, such as Excell and Global SST. Now, because the purpose of the present paper is not to investigate the reliability of the ITU-R model at low latitudes, we have abandoned its use at these latitudes in order not to bias the reader's perception of the various comparisons.

In conclusion, the comparison between GEO and GeoSurf paths shows that when the latitude is in the range of $\sim 20^{\circ} \mathrm{N}$ to $\sim 20^{\circ} \mathrm{S}$ (GEO elevation angle larger than about $67^{\circ}$ ), the GEO path is less attenuated, particularly at a probability of $0.01 \%$, which corresponds, of course, to high rain rates and very concentrated rain cells, differently sampled by the zenith path and the slant paths, as predicted by Global SST. At the zenith, the path is always filled with rain, while in the GEO slant paths, changing the elevation angle can make significant difference, because of the small linear extension of high intensity rain cells. Now, the path can be directed along the periphery of the cell, on average, as envisaged by the Global SST, which mimics what is directly observable with the full SST. This physical effect is also present, although just slightly pronounced, in the Excell model predictions.

In the next section, we calculate, for a specific case, the probability distribution of rain attenuation predicted for LEO satellites.

\section{LEO Probability Distributions of Rain Attenuation}

In this section, we show the expected tropospheric attenuation affecting LEO satellites. To this end, we have considered, as an example, the Metop-C satellite (launched on 7 November 2018), which is part of the EUMETSAT Polar System Constellation [30], as seen from Spino d'Adda. The constellation altitude is $817 \mathrm{~km}$, and the satellites provide data for both operational meteorology and climate studies. The instruments on board can observe the Earth day and night, as well as under cloudy conditions.

The satellite visibility was calculated by means of the simplified general perturbation model, which allows propagating the satellite position and velocity along the orbit [31]. The input to the model is given by NORAD and also stored on the EUMETSAT website (see https:/ / service.eumetsat.int/tle/, accessed on 5 November 2021).

As an example, Figure 8 shows the orbits and satellite track on the ground for $6 \mathrm{~h}$ (20 October 2021, starting time 20:07:26 UTC). Figure 9 shows two visibility windows, in terms of satellite elevation and azimuth angles, as seen from Spino d'Adda. Considering only elevation angles larger than $20^{\circ}$, there are typically three daily passes with an average duration of approximately 6 minutes and a maximum duration of roughly 7.6 min when reaching the zenith. 

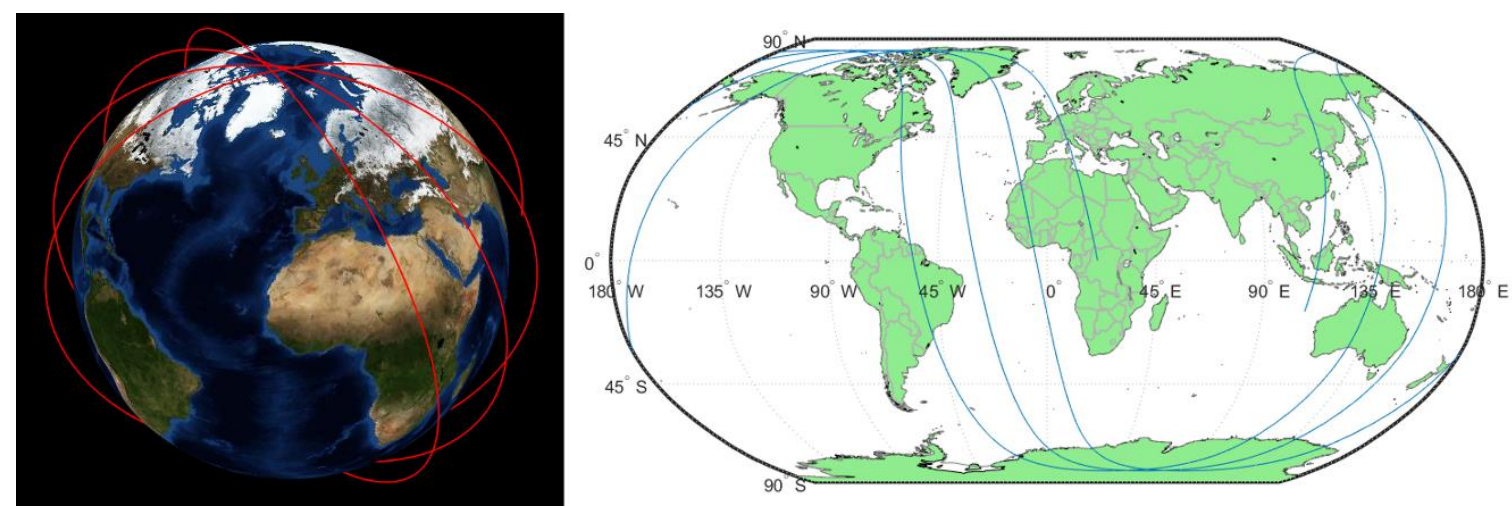

Figure 8. Orbits and tracks on ground of Metop-C satellite. 20 October 2021; starting time: 20:07:26 UTC.

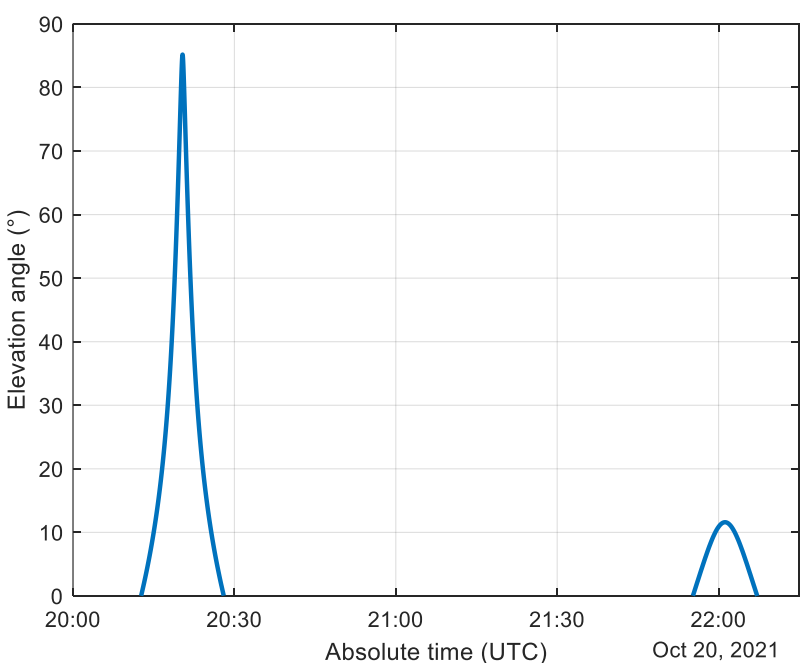

(a)

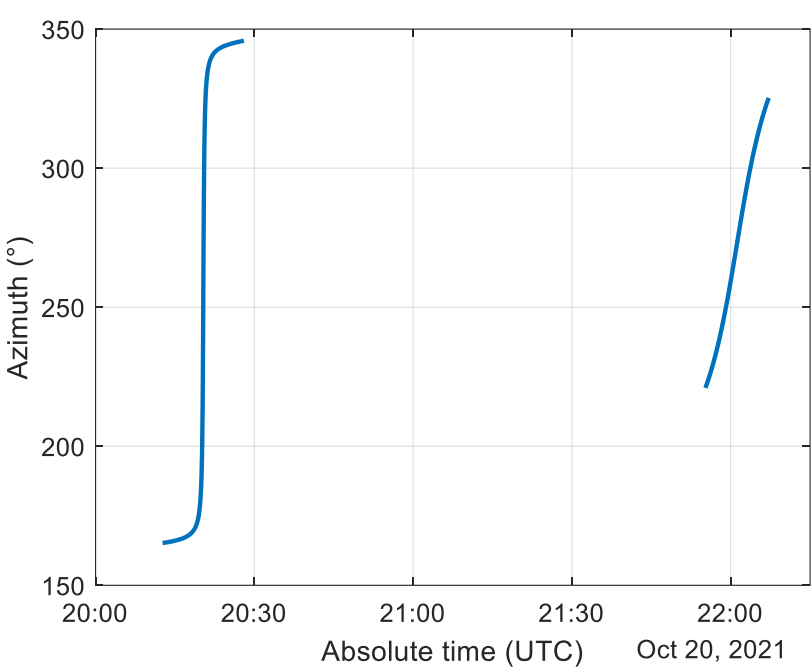

(b)

Figure 9. Sample visibility windows: Metop-C satellite seen from Spino d'Adda. (a): LEO satellite elevation angle. (b): LEO satellite azimuth.

We have simulated the Metop-C orbits for two consecutive months for providing a stable histogram and have calculated the probability of the elevation angle seen from Spino $\mathrm{d}^{\prime}$ Adda, whose histogram is shown in Figure 10 ( $5^{\circ}$ bins), for values large than $20^{\circ}$. This elevation angle is the minimum elevation tolerated in most LEO constellations, because at lower elevation angles, tropospheric fades, scintillation, and obstructions can produce severe outages. Afterwards, for each elevation angle up to zenith, we have calculated the probability distribution of rain attenuation predicted in each path and finally merged all probability distributions in the final curve by weighing each probability sample according to the probability shown in Figure 10. Moreover, we have supposed that sampling slant paths with an elevation angle larger than $20^{\circ}$ is also equivalent to sampling all possible rain events of the area, which, of course, produce the local rain rate probability distribution. This is a strong hypothesis but the only one that can be done at this stage for comparing LEO tropospheric attenuation with GEO or GeoSurf attenuation at equal probability. 


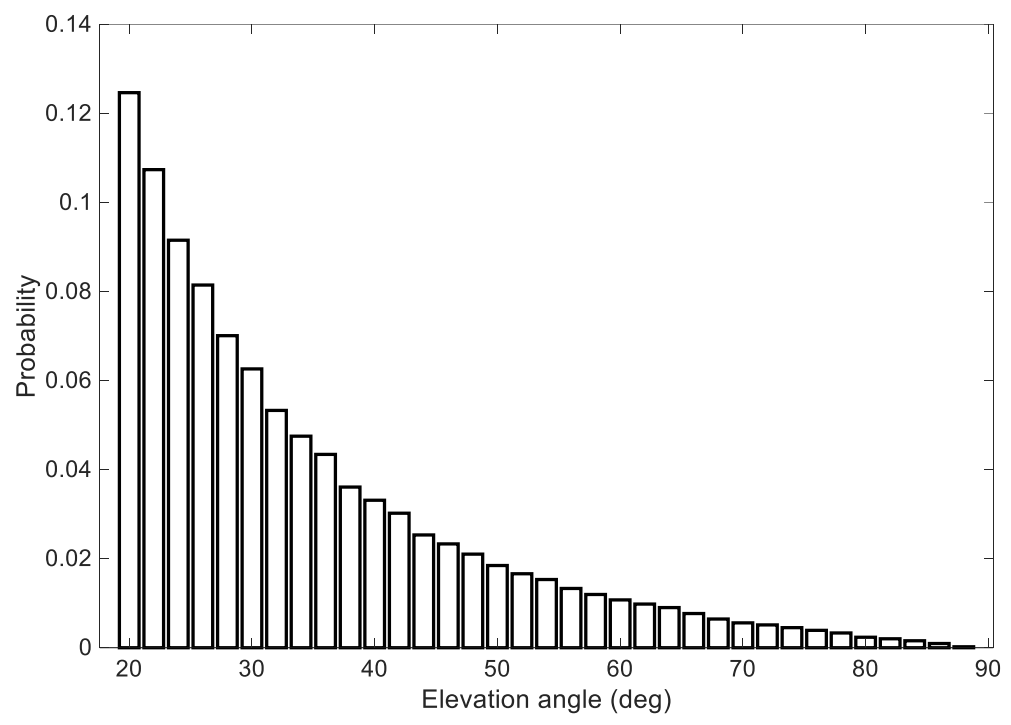

Figure 10. Probability density of the Metop-C satellite elevation angle seen from Spino d'Adda for elevation angles larger than $\sim 20^{\circ}$.

Figure 11 shows (left panel) the probability distributions of rain attenuation predicted for the LEO paths at the reference sites with the Global SST obtained by weighing the probability distribution of rain attenuation predicted for each elevation angle larger than $20^{\circ}$ according to the probability of the elevation angle shown in Figure 10. For comparing LEO and GeoSurf attenuation at equal probabilities, in Figure 11 (right panel), we show the difference $A_{L E O}-A_{Z}$ versus the annual probability (\%). From these curves, it is evident that GeoSurf "gains" several dBs compared to LEO. For example, at $0.1 \%$, $A_{L E O}-A_{Z} \approx 5 \mathrm{~dB}$ for Pasadena and Canberra, and $A_{L E O}-A_{Z} \approx 9 \mathrm{~dB}$ for Holmdel.

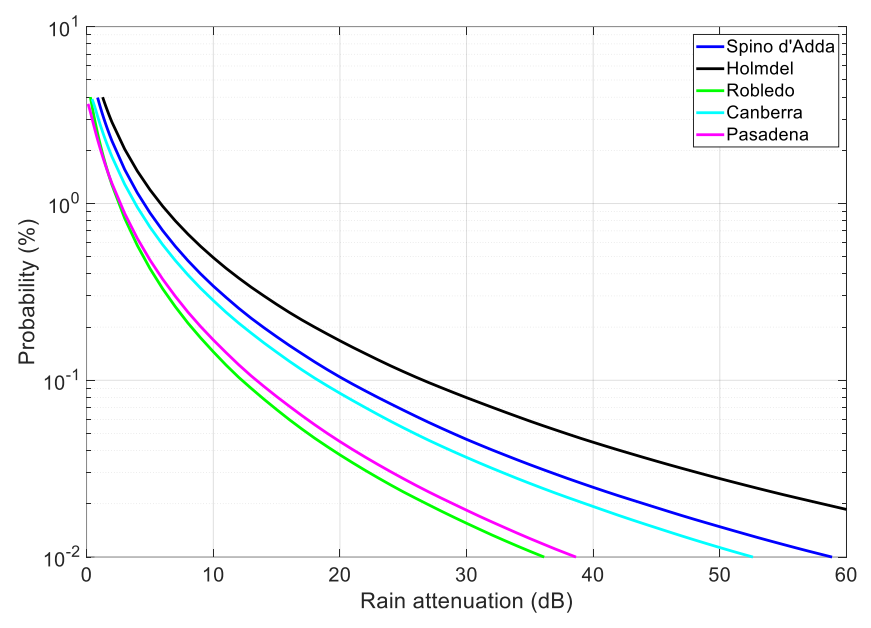

(a)

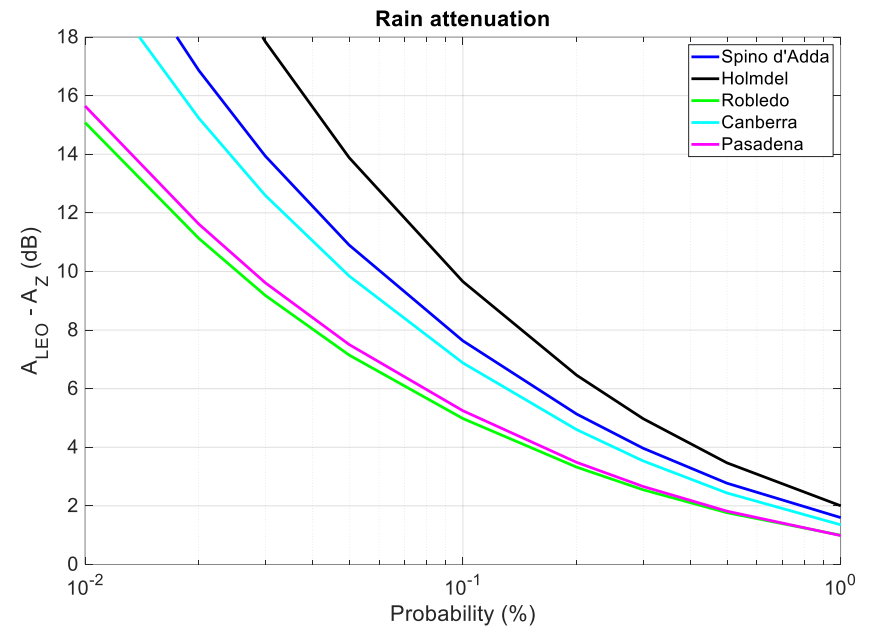

(b)

Figure 11. Results predicted with the Global SST model. (a) LEO annual probability distributions (\%) of rain attenuation at the reference sites, obtained by weighing the probability distribution of rain attenuation predicted for each elevation angle larger than $20^{\circ}$ according to the probability of the elevation angle shown in Figure 10; $39.6 \mathrm{GHz}$, at the reference sites. (b) The difference $A_{L E O}-A_{Z}$, vs. annual probability (\%), between the rain attenuation exceed in the LEO path, $A_{L E O}$, and the rain attenuation exceed in the GeoSurf path, $A_{Z}$, i.e., at the zenith at the reference sites.

In any constellation, the switchover between satellites is obviously mandatory for providing a continuous service. However, the number of switchovers and the interval between them, which is a function of the orbit altitude, increasing with altitude, should 
not change the results of our investigation in any significant way because rainfall and switchovers are, of course, uncorrelated.

\section{Global Clear-Sky Attenuation at $39.6 \mathrm{GHz}$}

In this section, we consider the total clear-sky attenuation due to water vapor, oxygen, and cloud, calculated with the ITU-R recommendations [32,33] at 39.6 GHz. Figure 12 shows the annual probability distributions predicted in the GEO paths on the local meridian of the reference sites. As for rain attenuation, the attenuation depends on site, with drier sites (Pasadena) being less affected than wetter ones (Holmdel).

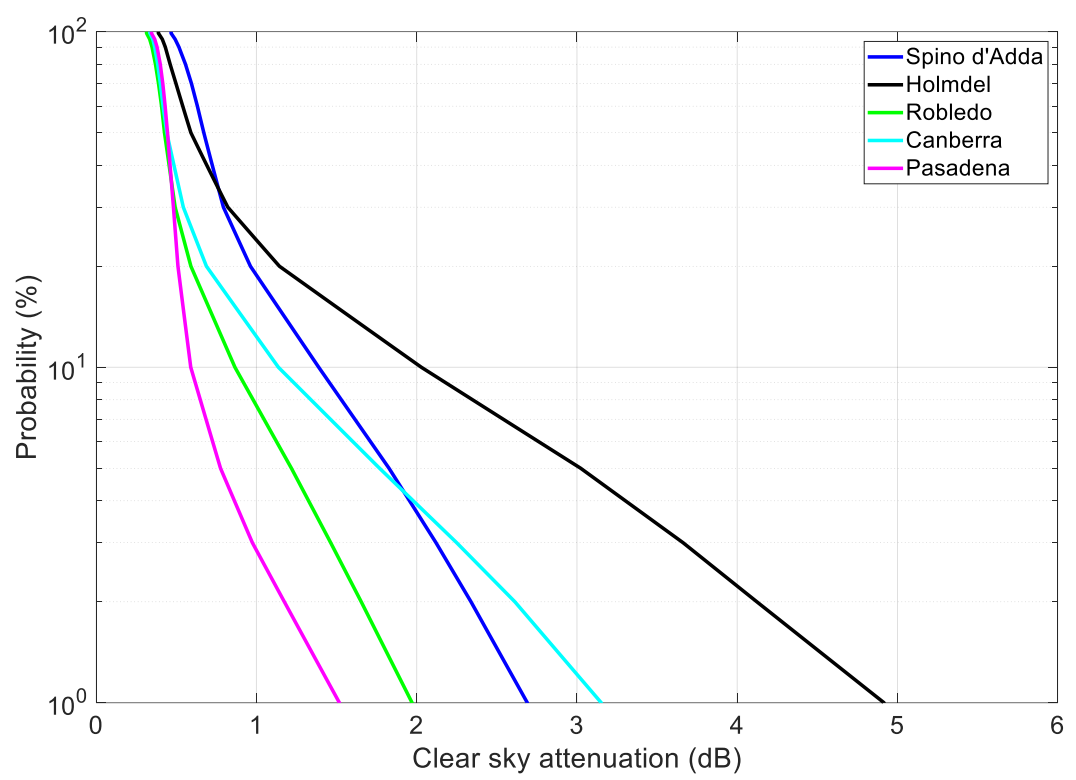

Figure 12. Annual probability distributions of clear-sky attenuation exceeded in the GEO paths on the local meridian at the reference sites.

Figure 13 shows the difference $A_{G E O}-A_{Z}$, calculated at the fixed annual probabilities of $1 \%, 5 \%$, and $10 \%$, between the clear-sky attenuation exceed in the GEO path, $A_{G E O}$, and that exceeded in the GeoSurf path, $A_{Z}$, in the latitude range $60^{\circ} \mathrm{N}$ to $60^{\circ} \mathrm{S}$ along the meridian of Spino d'Adda. We can notice that the Northern hemisphere is more attenuated than the Southern one. Now, even if the attenuation is smaller than that due to rain, it is always present because for probabilities below $1 \%$, the values do not significantly change; therefore, for any link design, the values exceeded at $1 \%$ should be considered. Figure 14 shows similar results for the other reference sites.

Now, for comparing LEO and GeoSurf attenuation at equal probabilities, in Figure 15, we show the difference $A_{L E O}-A_{Z}$, versus annual probability (\%), for the reference sites. From these results, we conclude that the GeoSurf should be affected, as expected, by smaller clear-sky attenuation. Because in system design we are interested in low probabilities and, as recalled, the clear-sky attenuation expected for probabilities below $1 \%$ is practically that estimated at $1 \%$, we can assume the values given by the black curves. As for rain attenuation, the Northern hemisphere is more attenuated than the Southern one. 


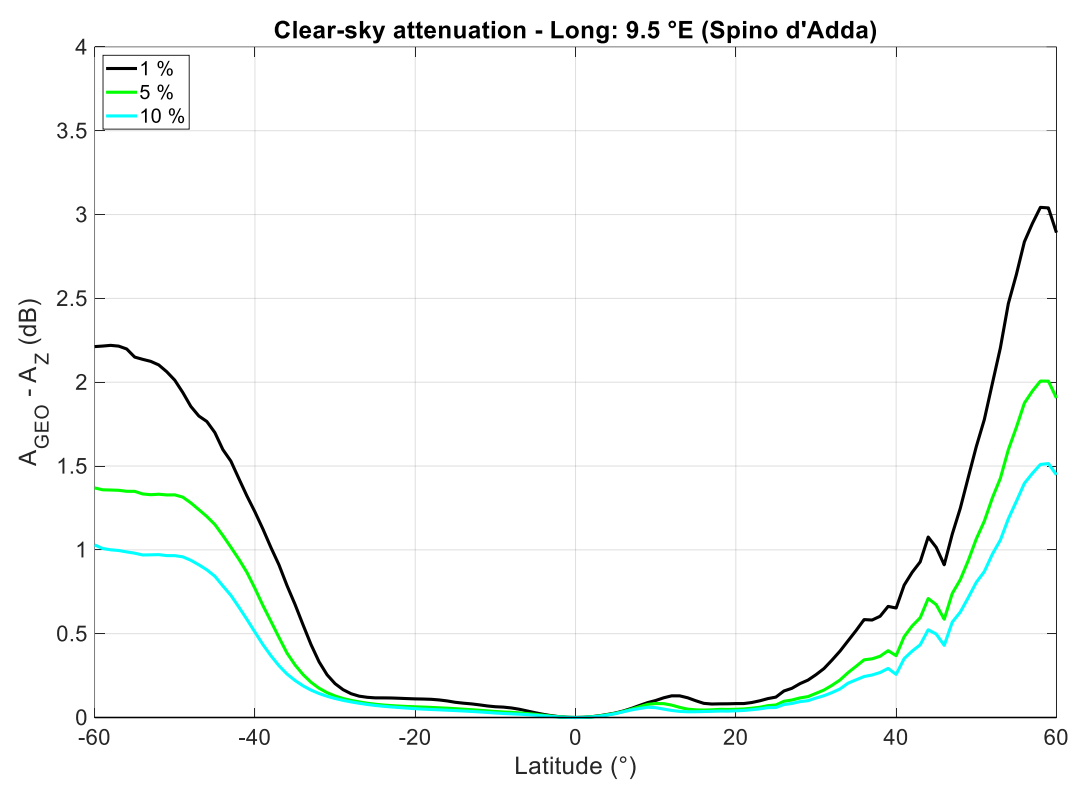

Figure 13. The difference $A_{G E O}-A_{Z}$, calculated at annual probabilities $1 \%, 5 \%$, and $10 \%$, between the clear-sky attenuation exceeded in the GEO path (elevation angle $37.7^{\circ}$ ), $A_{G E O}$, and that exceeded in the GeoSurf path, $A_{Z}$, along the meridian of Spino d'Adda $\left(9.5^{\circ}\right)$, in the latitude range $60^{\circ} \mathrm{N}$ to $60^{\circ} \mathrm{S}$.

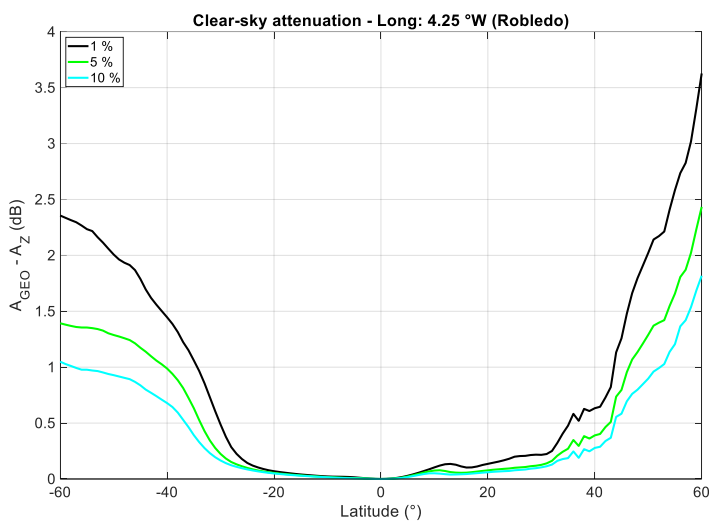

(a)

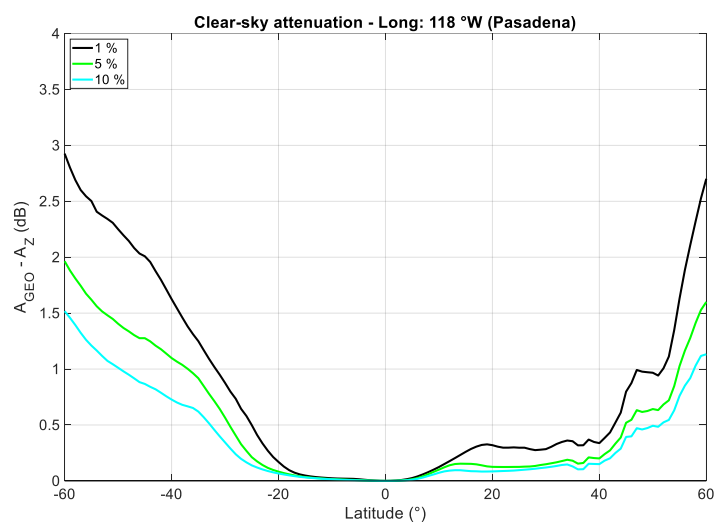

(c)

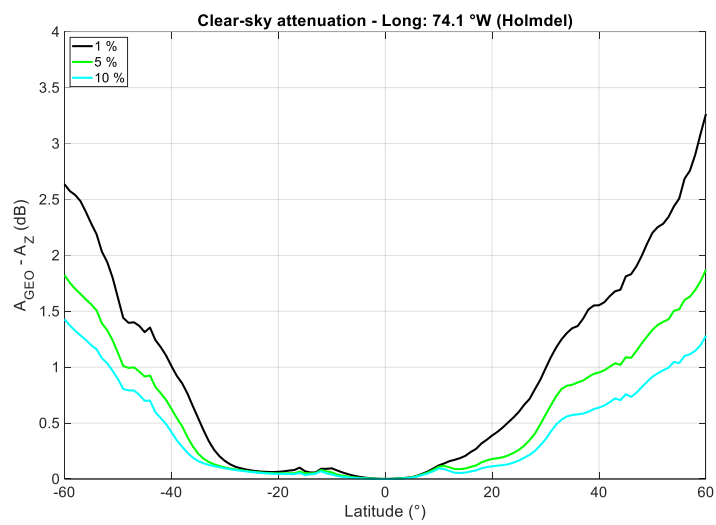

(b)

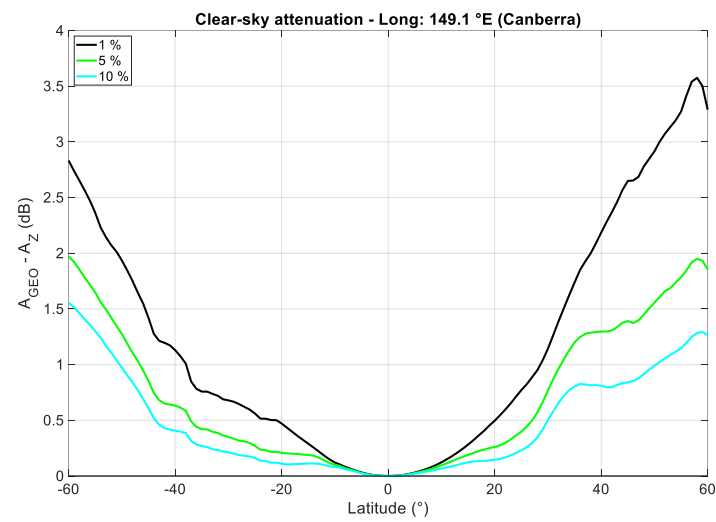

(d)

Figure 14. The difference $A_{G E O}-A_{Z}$, calculated at annual probabilities $1 \%, 5 \%$, and $10 \%$, between the clear-sky attenuation exceeded in the GEO path, $A_{G E O}$, and that exceeded in the GeoSurf path, $A_{Z}$, along the meridian of: (a) Robledo (GEO

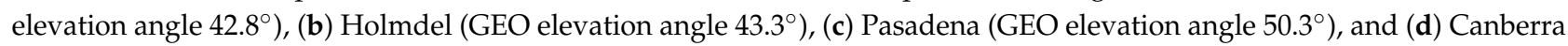
(GEO elevation angle $49.0^{\circ}$ ), in the latitude range $60^{\circ} \mathrm{N}$ to $60^{\circ} \mathrm{S}$. 


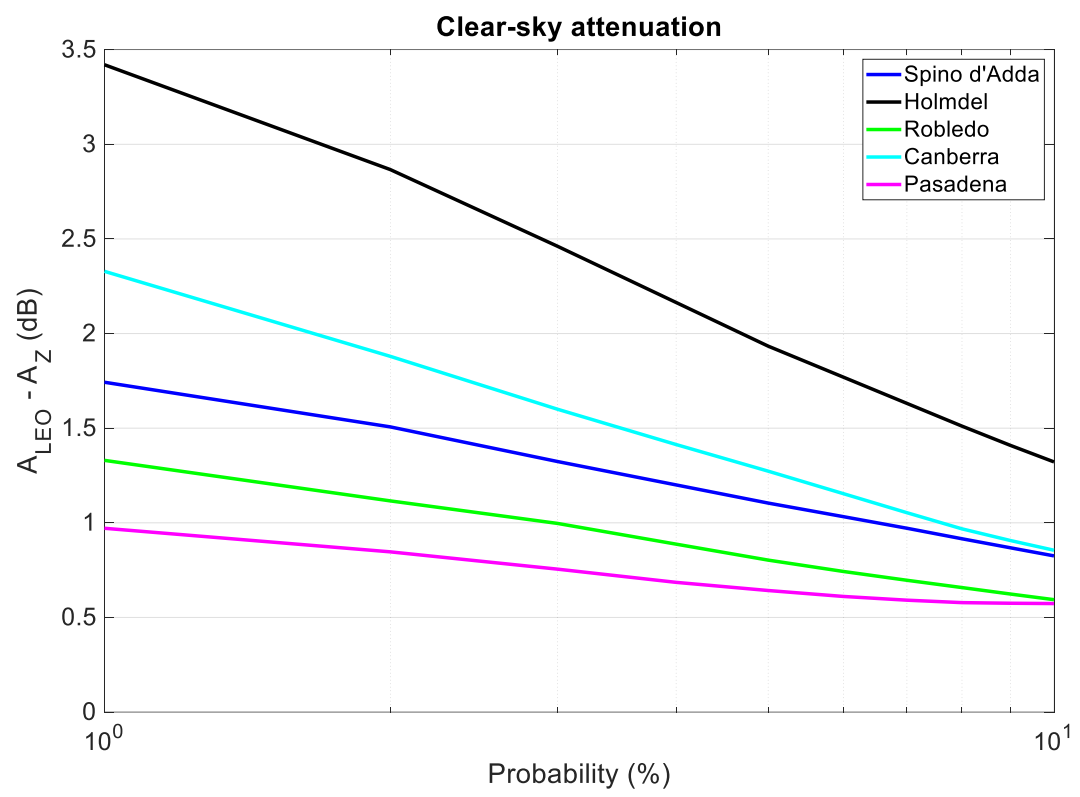

Figure 15. The difference $A_{L E O}-A_{Z}$, calculated, at equal probability, in the probability range $1 \%$ to $10 \%$ between the clear-sky attenuation exceeded in the LEO path, $A_{L E O}$, and that exceeded in the GeoSurf path, $A_{Z}$, in the reference sites.

\section{Final Remarks and Conclusions}

In GeoSurf satellite constellations, any transmitter/receiver, wherever it is located, can be linked to a satellite with zenith paths. In general, GeoSurf satellite constellations can have most of the advantages of the current GEO, MEO, and LEO satellite constellations without having most of their drawbacks [1].

In the present paper, we have studied one of the many feasibility issues that should be addressed before any industrial design is started, which is the tropospheric attenuation expected in the GeoSurf links, compared to other LEO satellite constellations and to GEO satellites. To be specific in predicting the annual average probability distributions of tropospheric attenuation, we have estimated both rain and clear-sky attenuation at 39.6 GHz. For link budget, once the outage probability is fixed, the total tropospheric attenuation exceeded at this probability sets the minimum signal-to-noise power ratio that must be provided to any link. Clear-sky and rain attenuation depend mainly on the frequency, site, and elevation angle under which the satellite is seen from the ground station.

For the purpose of illustration, we have studied the tropospheric attenuation predicted for some reference sites (Canberra, Holmdel, Pasadena, Robledo, and Spino d'Adda), which also set the meridian on which we have considered sites with latitudes ranging between $60^{\circ} \mathrm{N}$ and $60^{\circ} \mathrm{S}$. The choice of this particular latitude range is due to the fact that for larger latitudes, the GEO paths would be too low on the horizon to be practical and useful, whereas LEO and GeoSurf satellites can always be used at any latitude.

We have found that at high probabilities for system design (around 1\% of an average year), in the latitude between $30^{\circ} \mathrm{N}$ and $30^{\circ} \mathrm{S}$, there are no significant differences between GEO slant paths and GeoSurf zenith paths. On the contrary, significant differences are found for latitudes greater than $30^{\circ} \mathrm{N}$ or $30^{\circ} \mathrm{S}$ and lower probabilities. For example, along the meridian of Spino d'Adda $\left(9.5^{\circ} \mathrm{E}\right)$, at $60^{\circ} \mathrm{N}$, the average difference $A_{G E O}-A_{Z}$ predicted is about $5 \mathrm{~dB}$ at a $1 \%$ probability, $11 \mathrm{~dB}$ at $0.1 \%$, and $20 \mathrm{~dB}$ at $0.01 \%$.

In the low latitude range of $\sim 20^{\circ} \mathrm{N}$ to $\sim 20^{\circ} \mathrm{S}$ (GEO elevation angle along the meridian is larger than about $\left.67^{\circ}\right)$, the difference $A_{G E O}-A_{Z}$ is quite small, and even negative at a probability of $0.01 \%$, as most physical models (Global SST and Excell) retain some spatial features concerning small high-intensity rain cells.

For comparing the tropospheric attenuation in GeoSurf paths (zenith) with that expected in highly variable LEO slant paths, we have considered, as an example, a LEO 
satellite orbiting at $817 \mathrm{~km}$ as seen from Spino d'Adda and have supposed that it is also seen in the same way in the other reference sites.

From the results of our simulations using the Global SST, it is evident that GeoSurf zenith paths "gain" several dBs compared to LEO slant paths. For example, at a probability of $0.1 \%$, the minimum difference $A_{L E O}-A_{Z} \approx 5 \mathrm{~dB}$ is found at Pasadena and Canberra, and the maximum difference $A_{L E O}-A_{Z} \approx 9 \mathrm{~dB}$ is found at Holmdel.

We have also studied the more static total clear-sky attenuation (due to water vapor, oxygen, and clouds), which depends on the site and annual probability considered for link design. As expected, for any path, drier sites (Pasadena) are less affected than wetter sites (Holmdel). Moreover, both GEO and LEO slant paths show larger attenuation than GeoSurf (zenith) paths.

In general, both for rain and clear-sky attenuations, Northern and Southern Hemispheres show significant differences as probability decreases, especially for the larger latitudes.

Future work should be directed toward comparing the tropospheric attenuation expected in any LEO satellite constellation with that expected in a GeoSurf constellation globally, i.e., for any latitude and longitude.

Author Contributions: Conceptualization, E.M.; methodology, E.M. and C.R.; software, C.R. and L.L.; validation, all authors; investigation, all authors; data curation, all authors; writing-original draft preparation, E.M.; writing—review and editing, all authors.; visualization, C.R.; supervision, E.M. All authors have read and agreed to the published version of the manuscript.

Funding: This research received no external funding.

Data Availability Statement: The source of data used in this study is provided in the manuscript.

Acknowledgments: We gratefully thank Alberto Panzeri, Politecnico di Milano, for running some of the simulations.

Conflicts of Interest: The authors declare no conflict of interest.

\section{References}

1. Matricciani, E. Geocentric Spherical Surfaces Emulating the Geostationary Orbit at Any Latitude with Zenith Links. Future Internet 2020, 12, 16. [CrossRef]

2. Giannone, B.; Saggese, E.; Matricciani, E.; Paraboni, A. The ITALSAT propagation experiment. Space Commun. Broadcasting 1985, 3, 221-231.

3. Riva, C. Seasonal and diurnal variations of total attenuation measured with the ITALSAT satellite at Spino d'Adda at 18.7, 39.6 and 49.5 GHz. Int. J. Satell. Commun. Netw. 2004, 22, 449-476. [CrossRef]

4. Codispoti, G.; Parca, G.; Ruggieri, M.; Rossi, T.; De Sanctis, M.; Riva, C.; Luini, L. The role of the Italian Space Agency in investigating high frequencies for satellite communications: The Alphasat experiment. Int. J. Satell. Commun. Netw. Spec. Issue Alphasat Aldo Paraboni Ka Q/V Exp. 2019, 37, 387-396. [CrossRef]

5. Riva, C.; Luini, L.; D'Amico, M.; Nebuloni, R.; Marziani, A.; Consalvi, F.; Marzano, F.S. The Alphasat Aldo Paraboni propagation experiment: Measurement campaign at the Italian ground stations. Int. J. Satell. Commun. Netw. Spec. Issue Alphasat Aldo Paraboni Ka Q/V Exp. 2019, 37, 423-436. [CrossRef]

6. Attisani, A.; Capsoni, C.; Carassa, F.; Macchiarella, G.; Matricciani, E.; Mauri, M.; Paraboni, A.; Pawlina, A.; Poiares Baptista, J.P.V.; Vannini, C. The main results of the SHF-SIRIO experiment after two years of activity. Alta Freq. 1980, 49, 309-318.

7. Matricciani, M.; Riva, C. $18.7 \mathrm{GHz}$ tropospheric scintillation and simultaneous rain attenuation measured at Spino d'Adda and Darmstadt with Italsat. Radio Sci. 2008, 43, 1-13. [CrossRef]

8. Pontes, M.S.; Silva Mello, A.R. Progress on the Investigation of a Slant-Path Attenuation Prediction Method Based on the Complete Point Rainfall Rate Probability Distribution; CCIR: Geneva, Switzerland, 1992.

9. Bryant, G.H.; Adimula, I.; Riva, C.; Brussaard, G. Rain Attenuation Statistics from Rain Cell Diameters and Heights. Int. J. Satell. Commun. 2001, 19, 263-283. [CrossRef]

10. Capsoni, C.; Fedi, F.; Paraboni, A. A comprehensive meteorologically oriented methodology for the prediction of wave propagation parameters in telecommunication applications beyond $10 \mathrm{GHz}$. Radio Sci. 1987, 22, 387-393. [CrossRef]

11. Flavin, R.K. Satellite link rain attenuation in Brisbane and a proposed new model for Australia. Telstra Res. Lab. Rep. 1996, 8375, $1-15$.

12. García-López, J.A.; Hernando, J.M.; Selga, J.M. Simple rain attenuation prediction method for satellite radio links. IEEE Trans. Antennas Propag. 1988, 36, 444-448. [CrossRef] 
13. Matricciani, E. Global formulation of the Synthetic Storm Technique to calculate rain attenuation only from rain rate probability distributions. In Proceedings of the IEEE International Symposium on Antennas and Propagation, San Diego, CA, USA, 5-11 July 2008.

14. Svjatogor, L. Prostranstvennaia Korelacia Vypadenjija Dozdjej Vdol Zemnoj Poverchnostji (in Russian), Symposium Expertov Stran Uchastnic Programmy INTERKOSMOS (Interkosmos Symposium), Theme 5 of the Established Telecommunication Working Group, Dresden, Germany, 1985.

15. International Telecommunication Union. Propagation Data and Prediction Methods Required for the Design of EarthSpace Telecommunication Systems. In Recommendation ITU-R P.618-13; International Telecommunication Union: Geneva, Switzerland, 2017.

16. Martellucci, A.; Harris, R.A. COST Action 255, Radiowave Propagation Modelling for SatCom Services at Ku-Band and Above, Final Report; European Space Agency: Noordwijk The Netherlands, 2002.

17. Matricciani, E. Physical-mathematical model of the dynamics of rain attenuation based on rain rate time series and two-layer vertical structure of precipitation. Radio Sci. 1996, 31, 281-295. [CrossRef]

18. Matricciani, E.; Riva, C. The search for the most reliable long-term rain attenuation cdf of a slant path and the impact on prediction models. IEEE Trans. Antennas Propag. 2005, 53, 3075-3079. [CrossRef]

19. Kanellopoulos, S.A.; Panagoupoulos, A.D.; Matricciani, E.; Kanellopoulos, J.D. Annual and diurnal slant path rain attenuation statistics in Athens obtained with the synthetic storm technique. IEEE Trans. Antennas Propag. 2006, 54, 2357-2364. [CrossRef]

20. Matricciani, E.; Riva, C.; Castanet, L. Performance of the Synthetic Storm Technique in a Low Elevation $5^{\circ}$ Slant Path at 44.5 $\mathrm{GHz}$ in the French Pyrénées. In Proceedings of the 2006 First European Conference on Antennas and Propagation, Nice, France, 6-10 November 2006.

21. Acosta, R.; Matricciani, E.; Riva, C. Slant Path Attenuation and Microscale Site Diversity Gain Measured and Predicted in Guam with the Synthetic Storm Technique at 20.7 GHz. In Proceedings of the 2013 7th European Conference on Antennas and Propagation, Gothenburg, Sweden, 8-12 April 2013.

22. Matricciani, E. Space communications with variable elevation angle faded by rain: Radio links to the Sun-Earth first Lagrangian point L1. Int. J. Satell. Commun. Netw. 2016, 34, 809-831. [CrossRef]

23. Matricciani, E.; Riera, J.M. Variable elevation-angle radio links faded by rain at $\mathrm{K}_{\mathrm{a}}$ Band from Madrid to the Sun-Earth Lagrangian point L1. In Proceedings of the 22th Ka and Broadband Communications Conference, Cleveland, OH, USA, 17-20 October 2016.

24. Matricciani, E. Physical-mathematical model of dynamics of rain attenuation with application to power spectrum. Electron. Lett. 1994, 30, 522-524. [CrossRef]

25. Matricciani, E. Prediction of fade duration due to rain in satellite communication systems. Radio Sci. 1997, 22, 935-941. [CrossRef]

26. Matricciani, E. A Relationship Between Phase Delay and Attenuation Due to Rain and Its Applications to Satellite and Deep-Space Tracking. IEEE Trans. Antennas Propag. 2009, 57, 3602-3611. [CrossRef]

27. Matricciani, E. Probability distributions of rain attenuation obtainable with linear combining techniques in space-to-Earth links using time diversity. Int. J. Satell. Commun. Netw. 2018, 36, 220-237. [CrossRef]

28. International Telecommunication Union. Characteristics of precipitation for propagation modelling. In Recommendation ITU-R P.837-7; International Telecommunication Union: Geneva, Switzerland, 2017.

29. International Telecommunication Union. Rain height model for prediction methods. In Recommendation ITU-R P.839-4; International Telecommunication Union: Geneva, Switzerland, 2013.

30. Mattioli, V.; Accadia, C.; Ackermann, J.; Di Michele, S.; Hans, I.; Schlüssel, P.; Colucci, P.; Canestri, A. The EUMETSAT Polar System-Second Generation (EPS-SG) Passive Microwave and Sub-mm Wave Missions. In Proceedings of the 2019 PhotonIcs \& Electromagnetics Research Symposium—Spring (PIERS-Spring), Rome, Italy, 17-20 June 2019; pp. 3926-3933.

31. Vallado, D.A.; Crawford, P.; Hujsak, R.; Kelso, T.S. Revisiting Spacetrack Report \#3. In Proceedings of the AIAA/AAS Astrodynamics Specialist Conference, Keystone, Colorado, 21-24 August 2006.

32. International Telecommunication Union. Attenuation by atmospheric gases. In Recommendation ITU-R P.676-12; International Telecommunication Union: Geneva, Switzerland, 2019.

33. International Telecommunication Union. Attenuation due to clouds and fog. In Recommendation ITU-R P.840-8; International Telecommunication Union: Geneva, Switzerland, 2019. 